\title{
PRINCIPLES OF ENGINEERING DESIGN; TEACHING ACROSS DISCIPLINES
}

\author{
Jeff BARRIE ${ }^{1}$ and James NORMAN ${ }^{2}$ \\ ${ }^{1}$ Department of Engineering Design, University of Bristol \\ ${ }^{2}$ Department of Civil Engineering, University of Bristol
}

\begin{abstract}
This paper discusses the delivery of concept design principles across engineering disciplines, in particular between two programmes in engineering design and civil engineering. The paper discusses a 5 -week conceptual design project undertaken by first year civil engineering undergraduates, delivered from an interdisciplinary engineering design perspective and utilising a 'wicked problem' scenario. Key learning outcomes from the project were to enable students to demonstrate an appreciation of the environmental, economic, social, professional and interdisciplinary contexts, as well as scope and purpose of civil engineering, in delivering sustainable development. The students were able to demonstrate an appreciation of how civil engineering fulfils its purpose through design as a process of individual and collective learning; by undertaking a team-based design project with high level conceptual output, from creative visuals generated from AutoCAD and physical modelmaking using 3D printing and laser cutting. The students presented their design work to academic staff playing the hypothetical roles of different key stakeholders in the design process, as an engaging method of formatively assessing their learning outcomes. The project relies on very little to no understanding of engineering analysis; focusing instead on understanding stakeholder needs, creative output, and the principles of the conceptual design process in a civil engineering context. The outcome of the paper highlights the differences between conceptual design processes across disciplines, and levels of problem complexity. A group design project with limited technical complexity proved effective in attainment of high-level conceptual output and use of systematic methodology for analysing design options, whereas socio-economic and environmental considerations were explored in a wicked problem context.
\end{abstract}

Keywords: Civil engineering, conceptual design, 3D printing, prototyping, problem-based learning, multi-disciplinary, CAD, hackspace, makerspace, wicked problems, creativity

\section{INTRODUCTION \& METHODOLOGY}

Design; the ability to create and develop economically viable products, processes and systems to meet a defined need is a core competency required of all engineering disciplines for accreditation of MEng integrated master's degree programmes. As well as mastering science, mathematics and engineering analysis, engineering students are expected to face technical and intellectual challenges, integrating their engineering knowledge and skills, in solving real and complex problems as covered under current AHEP learning outcomes [1]. To achieve a balanced level of competency, first year engineering students should cover the basics of design as they would the principles of engineering maths, mechanics, thermodynamics and fluids. With a solid foundation of the core principles, further design projects can map additional outcomes as well as integrating them with other knowledge. Engineering programmes can lend themselves to be too focused on science \& mathematics and engineering analysis in the first year and assessed by exams. Design can be an intellectually challenging subject to learn and teach in engineering as students are assessed via coursework; there can be no model answer in an exam paper. As part of their Design and Computing 1 unit, 70 civil engineering students, at the University of Bristol, undertook a 5-week conceptual design project as groups of four. The major objectives of the project were to assess the students in the following main areas; understand and manage the design process, competence in using AutoCAD software for drawings and objects and an appreciation of the environmental, economic, social, professional and interdisciplinary contexts, with a scope and purpose of civil engineering in delivering sustainable development. The project assessed the student's CAD 
skills using AutoCAD, with the addition of producing models using laser cutting and 3D printing equipment in the engineering lab and faculty Hackspace facility; a creative space which is heavily used by engineering students for clubs, societies, Hackathon competitions and extracurricular work. Within mechanical engineering and design engineering disciplines, conceptual design entails problem solving, idea and concept generation and selection stages at the preliminary design phases of a project. This is also typical of the processes taught in the University of Bristol Engineering Design programme, which focusses of design and systems engineering. For example, a concept design process [2] is shown in Figure 1.

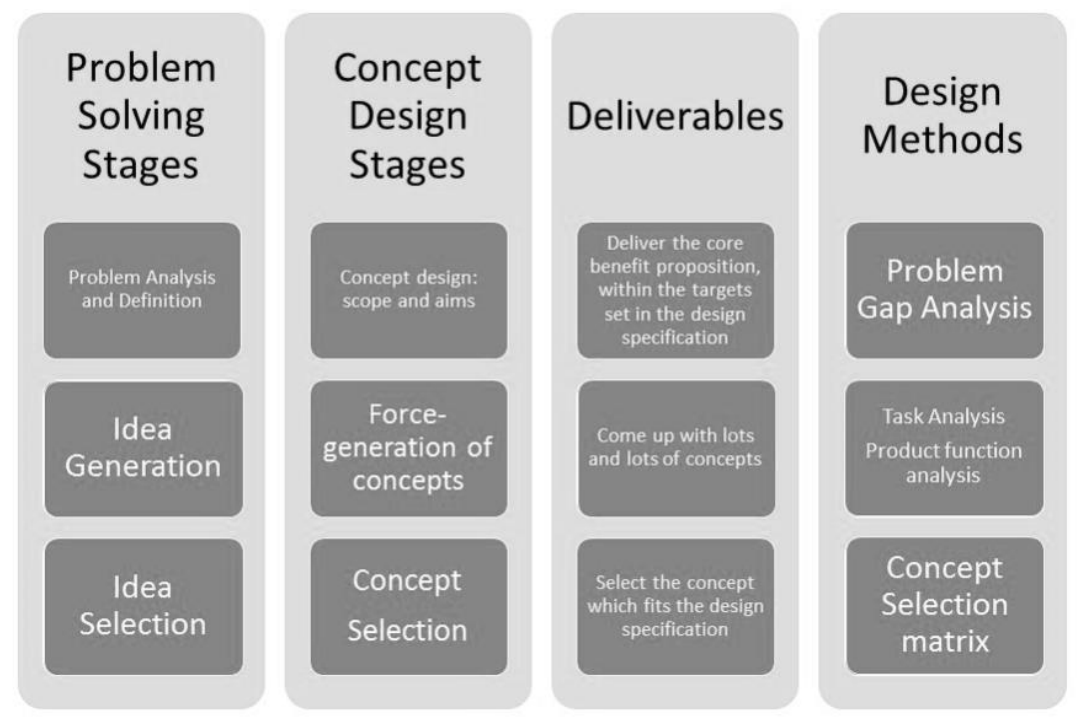

Figure 1. The concept design process (adapted from Baxter)

In Baxter's concept design model, structured techniques can be used to 'force generate' concepts, whereby reducing a complex design problem to its core elements. Whilst other systematic models exist, conceptual design is often represented as a one phase of the overall engineering design process. The following phases of engineering design tend to focus on embodiment, manufacturing and prototyping. Therefore, the conceptual design phase is critical in informing these latter stages. This has similarities within the context of civil structural design, where the preliminary design phase considers engineering, financial, economic and environmental feasibility, also using systematic methodology [3]. In the final design stages, the civil engineering design process becomes highly technical, analytical and codified [4], more so than a product or mechanical design model [5] which may stray away from dealing with real design issues [6]. Although innovation can exist in such phases, only in the preliminary design phase can creativity and high-level conceptual development be fully explored. One may argue that the concept design aspect of a civil structure is the responsibility of an architect, and the technical construction lie with the civil engineer. However, close collaboration in design teams is of the utmost importance in modern civil engineering and advanced structural design, as is the relationship of an industrial design and mechanical engineer in product design [7]. Literature on systematic design processes for civil engineers is not as wide as other disciplines, but convergent and divergent thinking, understanding design requirements and evaluating solutions are applicable to the built environment [8]. Civil engineering deals with enormous scope and complexity with large design teams, project planning, risk management and multiple stakeholders in the process. Engagement with the public is critical, as well as considering socio-economic and environmental factors in a changing world. Such complexity can be tackled using a design thinking and a wicked problem approach as design, by its nature, is not true or false (just good and bad) [9]. Wicked problems are suited to type of projects civil engineers undertake [10] as they attempt to meet the demands of conflicting stakeholder views and balancing environmental and socio-economic factors. There is a perception that engineering, particularly civil engineering, is an uncreative discipline; but there are positive pedagogical and business case benefits for introducing creativity and PBL in the subject [11] [12]. 


\section{PROJECT STRUCTURE, ASSESSMENT \& RESOURCES}

For the conceptual design project, students were assessed through a poster submission and presentation of a physical model, focusing on areas of brainstorming, stakeholder analysis, understanding design requirements, seeking alternative designs and communicating design via $\mathrm{CAD}$ and physical models. The delivery of the project was supported by CAD sessions and design studio activities, as well as workshop and Hackspace inductions to enable physical modelmaking using whatever creative output the students deemed fit as long as the models were generated from CAD (using 3D printing and laser cutting). The project followed the initial stages of a systematic concept design process, where the first week was dedicated to identifying needs, opportunities and coming up with initial ideas and sketches. The second week focused on defining design requirements, understanding constraints and evaluation of concept level designs. In the third week, CAD classes began, and students developed their chosen concept design using AutoCAD. In the fourth week the students prepared and submitted design work in poster format. Students presented their work as part of a group presentation to stakeholders in the final week. As the Design and Computing 1 unit contained many learning outcomes relating to engineering analysis, it was appropriate to minimise this aspect in the project such that students focused on the core elements of design. Methods such as the pairwise comparison chart and Pugh conversion matrix were borrowed from techniques delivered in the interdisciplinary engineering design programme and stripped down into a simple systemic process. The civil engineering cohorts' outcomes were compared with that of engineering design to evaluate its effectiveness; both cohorts had small numbers (less than 100 students), similar ages (17-18 years old) as well as female to male ratio (approx. $35 \%$ female). The projects would be, for most students, the first detailed design project they would have undertaken. The process can be seen in Figure 2.

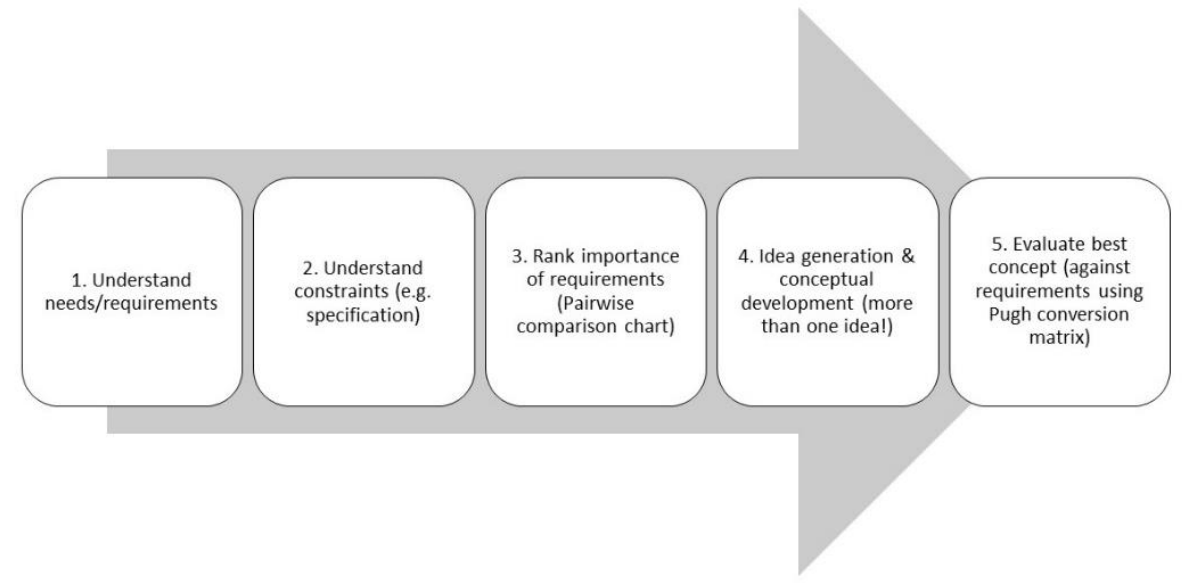

Figure 2. A simplified conceptual design process showing key steps (adapted from Baxter)

\section{PONTY BRIDGE - A REAL 'WICKED PROBLEM'}

It was important to ensure that the task set out for the civil engineering students was not deemed as trivial and, albeit a creative exercise, had some constraints and controlled outcomes. In keeping with the conceptual theme, it was important that students understood the value and meaning of civil infrastructure to various stakeholders and communities. Although it is encouraged for civil engineers to take an international view and engage with engineering projects across the world, domestic issues can also prove to be challenging and insightful. In recent years, the United Kingdom has been subject to flooding and weather-related disasters which have impacted on rural communities, one of the highest profile crises being the flooding of the Somerset levels in 2014 [13]. During this crisis, there were socio-cultural and economic issues brought up concerning the Environment Agency, local councils and volunteers, the Dept of Environmental and Rural Affairs (DEFRA) and campaign groups. The Environment Agency was accused of neglecting local rivers, and the Environment Secretary at the time, Owen Paterson, was confronted by angry locals who believed the damage to their properties, businesses and livelihoods was attributed to a failure to dredge the rivers. During winter flooding in 2015 , the $16^{\text {th }}$ century bridge in Pooley Bridge, Cumbria was washed away when the river burst its banks. This event had a profound impact on the community, as the town relied on tourism; and the bridge provided a road access point. A 
new bridge design was commissioned in 2017 [14] and this required extensive stakeholder engagement with the local community, councils and the Environment Agency. A major concern of the project from the parish council was the construction time, which would cause disruption to the town's major tourist season, however the county council were bound by the Environment Agency, due to concerns about the effect on sustainable fish stocks. The architects also had to balance a new, cost effective and flood resistant structural design while respecting public opinion and the towns rural setting. See Figure 3.
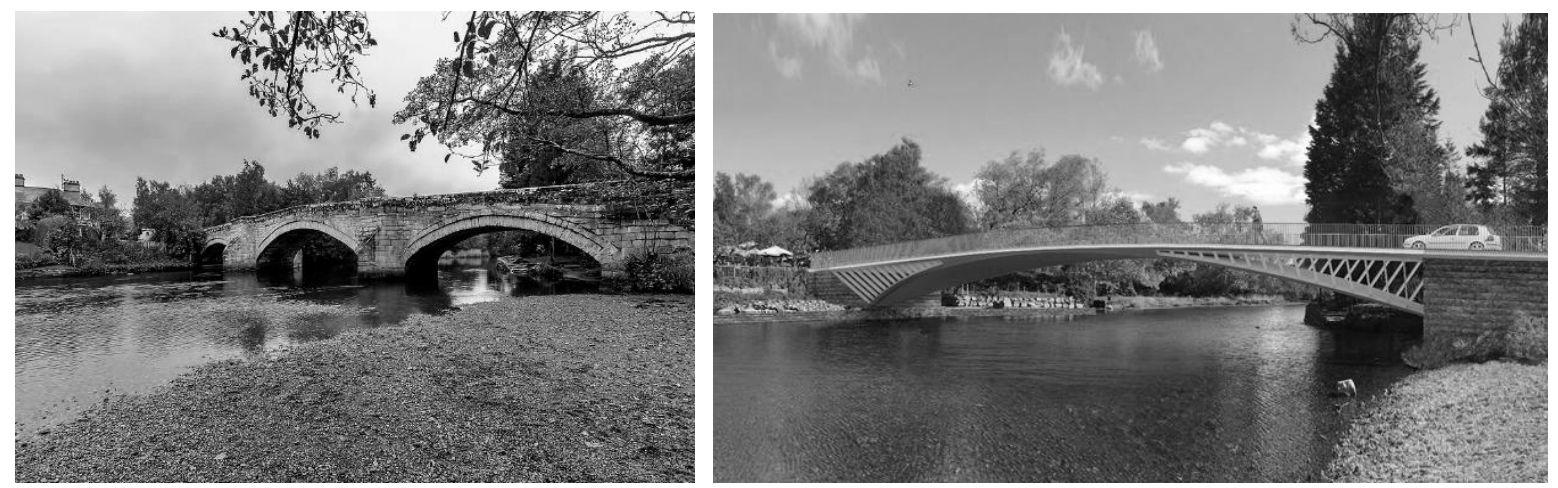

Figure 3. The $16^{\text {th }}$ century Pooley Bridge (left) \& 'new' Pooley Bridge (right)

This context provided real-world design problems to draw from, including a feasible and viable solution outcome. Location details were changed, and the scenario was relocated to Wales. To complete the deception, an imaginary public consultation (with divergent views and opinions) were mixed with real quotes from the Barton parish council and Cumbria county council. Therefore, students were given similar conflictive requirements and context to a complex real design problem. The outset of the conceptual design project asked students to review the information in the first week. This included a fake public consultation, photographs, a fake Environment Agency report and discussion between two main stakeholders, the parish council and county council. The students were provided with cost driver and construction design metrics, which influenced the conceptual direction students could undertake without the need for analysis. Cost constraints were imposed by county council funding and an 'aesthetically pleasing and traditional' stone bridge would impact severely on time to build and cost. Contradictory design features such road infrastructure and flood prevention were introduced to 'improve' the bridge design by having 2 lanes of traffic or increasing the weight limit; both having an impact on cost and the inclusion of supports/arches-which subsequently increases the risk of flooding. See Figure 4.
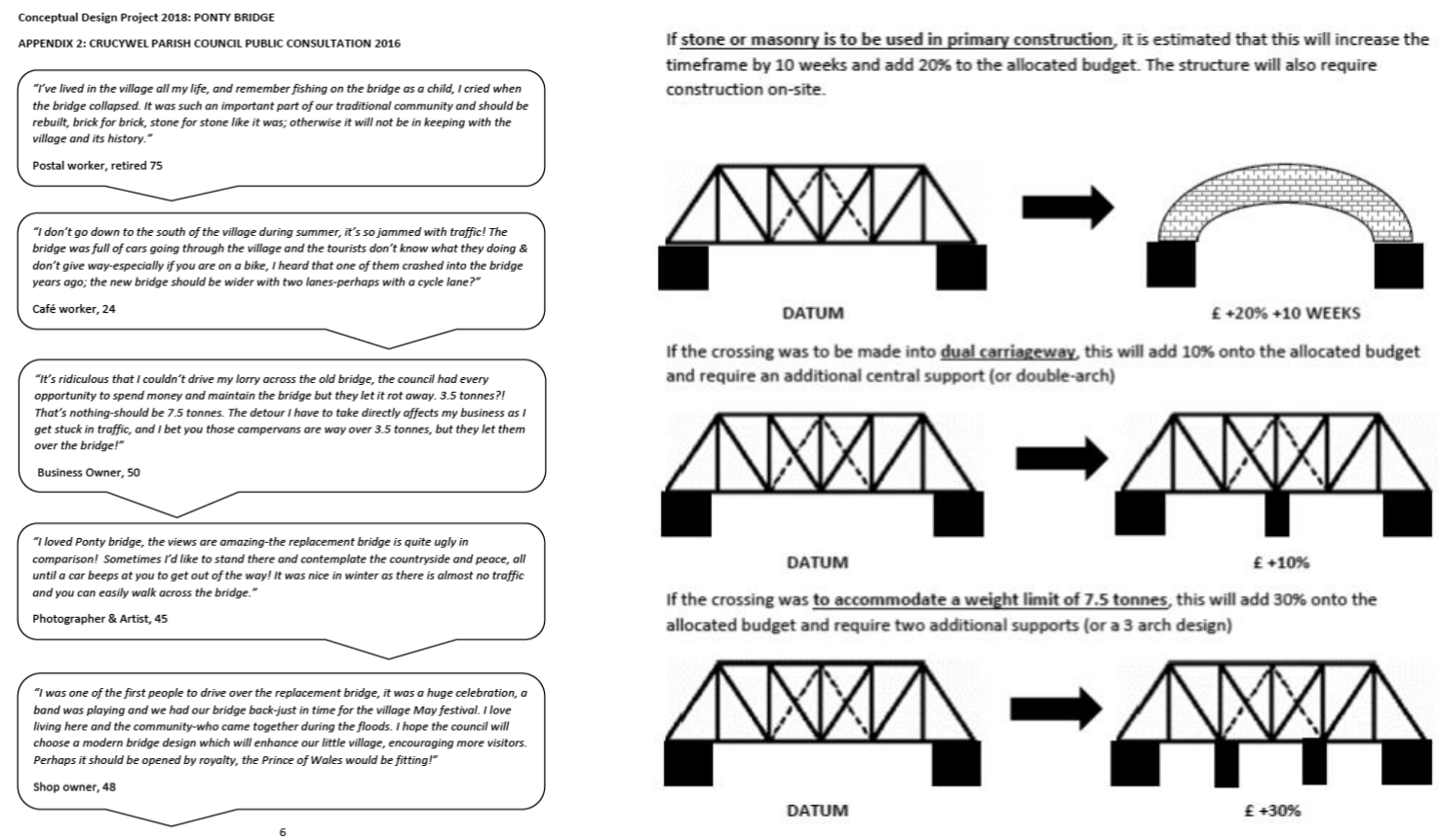

Figure 4. A fake public consultation (left) \& cost and construction metrics (right) 
By removing analysis, students focused on idea generation, stakeholder needs and design requirements. Students were able to produce a broad range of creative concept sketches, some inspired by natural surroundings and local history. In the final assessment, student groups presented a 5 minute presentation pitch to the three main stakeholders, the parish council, county council and Environment Agency. Although there is no 'model' solution, students should have considered flood prevention and cost as highly weighted requirements in their design, and a simple single span bridge is more feasible and viable than an over engineered solution. Each stakeholder had a conflictive requirement of what a good and bad design is; for example, the county council focused on cost effectiveness. As defined by the wicked problem scenario, students learned that it was almost impossible to appease all stakeholders wishes and had to compromise. See Figure 5.
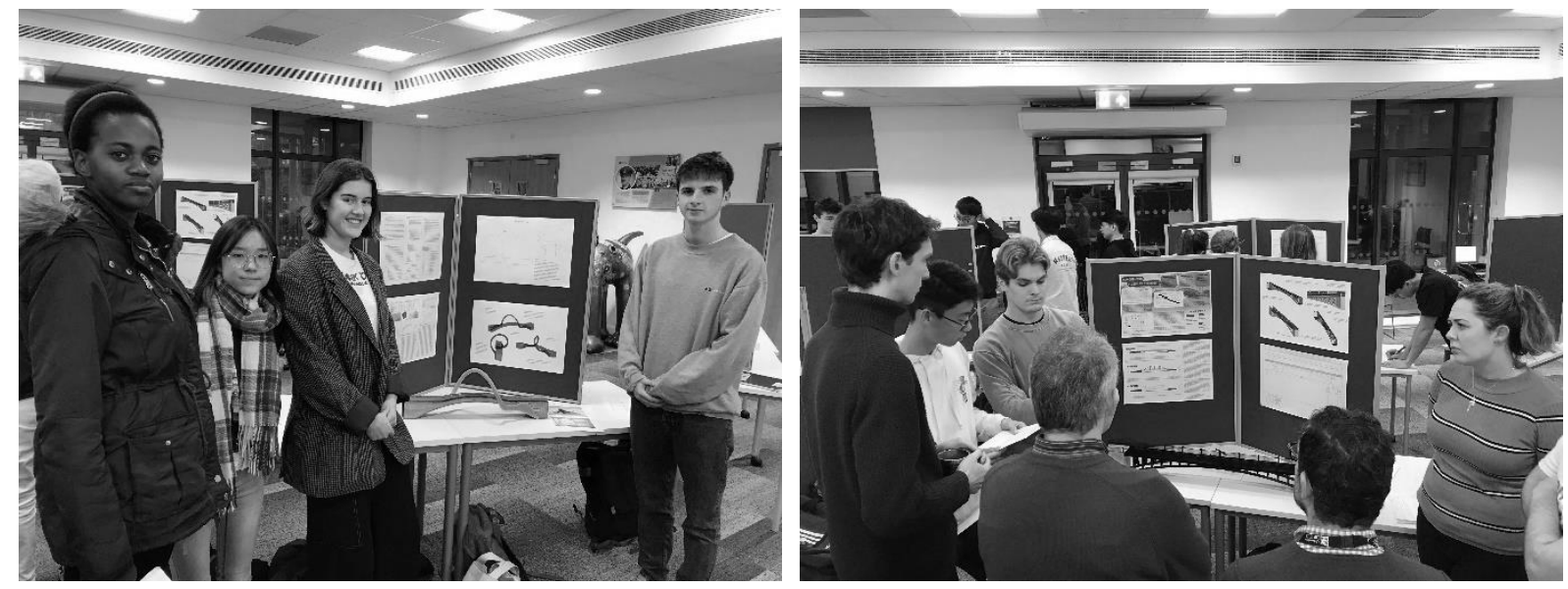

Figure 5. Student poster presentation \& model (left) and stakeholder discussion (right)

\section{MEASURING SUCCESS - DO CIVIL ENGINEERS UNDERSTAND CONCEPTUAL DESIGN?}

The civil engineering project outcomes were compared against those of engineering design students, who were undertaking a more mechanical focused product design exercise over the course of the term. The engineering design students had to consider other factors such as manufacturing as well as engineering analysis. The engineering design students were given the same conceptual design methods and tools. Comparing the 19 group submissions of the civil engineering students against the 32 individual submissions of the engineering design students, $100 \%$ of civil engineering student submissions were able to show a clear understanding of needs and design requirements, and conceptual development beyond one idea or design (where engineering design achieved 69\% and 63\% respectively). The civil engineers used pairwise charts more effectively (63\% against $41 \%$ ) and concept evaluation tools ( $42 \%$ against $25 \%$ ). Engineering design students understood constraints better via the use of a specification (84\% against 32\%). Civil engineering students were able to excel in their understanding of conceptual design in a short time. Both projects had creativity and CAD elements, but only the civil engineering design group project had the resources and freedom to explore and make physical models in the hackspace. The individual nature of the engineering design project somewhat limited this scope. Qualitative feedback was obtained by two female representatives of the civil engineering cohort on the 'wicked problem' scenario. One student exclaimed that this was one of the most challenging projects they had ever done, as there was no clear right or wrong answer, and could not be solved using calculations or engineering analysis. The other student reflected that the whole project concept was very good and helped understand the importance of stakeholders and budgets in the beginning of design. Furthermore, it helped with developing concepts for latter design projects in their studies.

\section{DISCUSSION AND CONCLUSIONS}

There is merit in working in a group, and a better chance that individual attainment of learning outcomes can be shared among peers. By working in groups, with analytical elements simplified and prescribed, there is better attainment of design related learning objectives. A group will be able to tackle more complex problems by breaking it down into design elements. If additional calculations and engineering 
analysis are applied, it may be that there is distraction on other tasks it was noted that $100 \%$ of the engineering design students performed engineering analysis of their conceptual design but over $30 \%$ of the class failed to show a broad range of conceptual development. The typical approaches used in mechanical and engineering design cohorts can fall short due to their technical driven nature and such application of analysis at this the conceptual stage of the design process was trivial, as it did not assist in forming any sort of a conceptual design direction. Of the $30 \%$ of engineering design students a single idea or concept was developed. However, with the students who developed a range of concepts only $25 \%$ used an evaluation tool to choose the best design. Although some rationale was evident, it was clear that students stuck with a design or idea unchallenged, with limited use of methods/tools. The civil engineering cohort embraced the tools, and this could be attributed to there being differing viewpoints among the group of what the best concept design is (although there may be a danger of groupthink in those who did not utilise the tools). Some civil engineering design groups were able to express a broad range of conceptual creativity and an appreciation of aesthetics which was unexpected in a civil structural design project. To conclude, all engineers can benefit from a systemised conceptual design process, and the use of a real-world wicked problem (with no 'right' or 'model' answer) can make a design project relevant to a discipline, challenging, yet controlled and ultimately more engaging. There may be some benefit in using groupwork to make decisions at the conceptual design phase to limit individual bias and use evaluation tools effectively. One can question if engineering analysis is necessary or suitable for the early conceptual stages of a design project. Students could be over focusing on technical aspects rather than broadening their conceptual development; leaving less time to explore, be creative and have fun.

\section{REFERENCES}

[1] The Accreditation of Higher Education Programmes-UK Standard for Higher Education Programmes-Third Edition 2014 (EAB Form ACC1-Appendix A).

[2] Baxter M. Product Design-Practical Methods for the systematic development of new products CRC Press 1995.

[3] Grigg N.S. et al Civil Engineering Practice in the Twenty-First Century: Knowledge and Skills for Design and Management ASCE Press 2001.

[4] Chanakya A. Design of Structural Elements: Concrete, Steelwork, Masonry and Timber Designs to British Standards and Eurocodes.

[5] McLaren A. Approaches to the Teaching of Design-an Engineering Subject Centre Guide Higher Education Academy Engineering Subject Centre 2008.

[6] Barrie J. Same Same But Different: Core Design Teaching in Mechanical Engineering International Conference on Engineering and Product Design Education 6\&7 September 2018, Dyson School of Design Engineering, Imperial College London, UK.

[7] Larsen O.P. Conceptual Structural Design: Bridging the gap between architects and engineers ICE Publishing.

[8] Jones J.C. Systematic design processes and the building design process Fraunhofer Information Centre for Space and Construction IRB Available:

http://www.irbnet.de/daten/iconda/CIB15018.pdf [Accessed on 2019, 22 May].

[9] Buchanan R. Wicked Problems in Design Thinking. Design Issues Vol 8 No. 2 pp 5-21 The MIT Press 1992.

[10] Rameley J.A. The Changing Role of Higher Education: Learning to Deal with Wicked Problems Journal of Higher Education Outreach and Engagement, Volume 18, Number 3, p.7 2014.

[11] Stouffer W.B. et al. Making the Strange Familiar: Creativity and the Future of Engineering Education Proceedings of the 2004 American Society for Engineering Education Annual Conference \& Exposition (ASEE) 2004.

[12] Gavin K. Case Study of a Project-based Learning Course in Civil Engineering Design. European Journal of Engineering Education, 2011.

[13] BBC News. Somerset Level Crisis: How the story unfolded Available: https://www.bbc.co.uk/news/uk-england-somerset-26157538 [Accessed on 2019, 28 Feb], (2014) 19 March.

[14] Cumbria County Council Pooley Bridge Replacement Bridge Project https://www.cumbria.gov.uk/pooleybridge/ [Accessed 2019, 19 Feb], 2019. 